\title{
STUDY OF THE PROTECTION LENGTH DOWNSTREAM OF FAY TYPE WEIRS WITH OPENINGS
}

Tarek H. Nassralla, Ahmed A. Abdelaziz

\begin{abstract}
Weirs may be used for flow measurements, energy dissipation, regulation of flow depth etc. Most of the pr studies focus on discharge coefficient of combined flow, Little information is available on local scouring dov these structures. So, the aim of this research is to study the influence of using openings in weirs on scour downstream. A total of 171 experimental runs were carried out in a recalculating rectangular flume, $A$ moc type weir with openings was fixed in the flume bed. Two cases of opening arrangements were included, on and three openings. Different diameters of openings, $1.27 \mathrm{~cm}, 1.9 \mathrm{~cm}$ and $2.54 \mathrm{~cm}$, different weir height $\mathrm{r}$ 0.25 and 0.5 were tested under the same flow conditions. The experiments illustrated that for most of the opening diameters in either case, one opening or three openings, the ratio $\mathrm{h} / \mathrm{p}=0.25$ gave smaller values length, while the ratio $h / p=0.5$ gave higher values. Also, it was noticed that the case of one opening for $r$ considered opening height, the ratio $d / p=0.149$ gave smaller values of scour length but for case of three ratio $d / p=0.075$ gave smaller values
\end{abstract}

